\title{
Proposal for an Automated Form Finder System to Deduce the Authentic Morphology of Siirt Cas Houses
}

\author{
Mehmet Gökhan Berk ${ }^{(\bowtie)}$ \\ Yildiz Technical University, Istanbul, Turkey \\ mgokhanberk@gmail.com
}

\begin{abstract}
This paper aims to summarize the steps taken towards the development of a semi-automated system in an attempt to create computer modeling of the original morphology of the individual buildings and respective urban texture for the so called "cas" houses which are the characteristic traditional buildings of the Siirt Province in Turkey. For the purpose of developing the proposed system, the architectural space forming methods that are closely related with the structural composition of the buildings where loose stones are joined with a strong and quick drying mortar are observed. It has been detected that cas houses are in fact built in time through an incremental expansion approach making use of repeating rectangular cells in horizontal plane coming side to side, and upper floor plans are developed almost identically to ground floor layout. The rhythmic layout of the façade elements such as doors and windows, cut rectangular pyramidal form of the buildings and specific elements such as stair covering vaults and underpasses are both enriching the building form and enabling easier detection of the original morphology of the buildings. The proposed form finding system is based on the principle of processing the approximately measured outer boundaries of the existing buildings to deduce internal spaces' sizes and layout which are in fact the sole sources causing the exterior building form for cas houses.
\end{abstract}

Keywords: Siirt cas houses $\cdot$ Heritage modeling $\cdot$ Automated plan generation

\section{Introduction}

Architectural heritage at relatively less developed regions is under high risk of decay, deterioration and extinction mainly due to the owners' inadequate resources for maintenance, inadequate or lacking funding for conservation initiatives as well as due to poor awareness about the heritage value of such buildings. Interventions to this kind of buildings mainly aim to maintain and/or improve the buildings for daily practical needs or for expectations of adaptation to changing lifestyles without much sensitivity towards the original and authentic characteristics and generally results in degeneration and loss of valuable information with regards to regional, traditional and historical aspects. For such buildings it is not unusual to see that the original details are removed and the general form of the buildings is obscured during renovations and other interventions, thus the main heritage character is lost or concealed. 
It is extremely difficult, almost impossible to bring back value, or further preserve such spoiled and degenerated buildings and reinstate the built environment to its original state, however much can be done by exploring the most appropriate methods, systems and intervention rules through fictionalizing the future they are destined to, with conservatory planning decisions that value the inherent authentic characteristics. This kind of interventions need to consider numerous parameters including but not limited to social environment, economical value, urban movements, population and other demographic aspects besides the local architectural, spatial, structural and planning decisions and initiatives.

Two extreme opposed intervention logics at such situations are towards either gentrification of this kind of buildings and neighborhoods, or towards urban regeneration through a totally changed character. It is obvious that more elaborated mechanisms are needed in search of a more accurate approach ensuring coherence of physical built environment with social needs, open to improvement and development through still preserving the authenticity and heritage value of buildings and respective neighborhood.

Clearing the extrinsic interventions, conservation and restoring the original and authentic form of historical buildings and neighborhoods is a complex process even on drawings and virtual models. Contemporary digital technologies are providing large opportunities for exploring, inducing and modelling the original form of buildings with heritage value and respective physical built environment. It is now possible to build three dimensional models of the historical neighborhoods at a given moment in time although this kind of studies can be quite difficult, time, resource and effort consuming due to the complexity of the buildings and respective physical environment as well as due to the considerable need for background information to be extracted from documentary and photo archives.

The amount of manual work may be remarkably reduced in parallel to recent advances in technology such as three dimensional scanning devices, and advanced modelling software but the large number of information and point sets created still require a considerable effort for evaluating and processing the acquired data. This fact imposes a need for automatic and/or intelligent methods and systems for registering, merging, abstracting and processing in defined ways of large range of data sets. It is also possible to employ this kind of intelligent systems to predict missing information to deduce not only geometrical but also other types of information that might explain the shaping of the built environment either by human behavior or by other forces.

This paper aims to investigate possibilities for developing systems capable of modelling authentic forms of the urban texture and individual buildings through use of generative computer-aided systems which are supposed to make use of the inherent grammar of the concerned historical buildings and urban texture. 


\section{Computer-Aided Form Generating Systems}

\subsection{Broad Overview of the Form Generating Systems}

Use of the generative computer aided systems for form finding process in architectural design has been a considerably researched topic since a few decades. In essence these systems are based on computer processed algorithms which are according to Rajaraman, specifications of a sequence of instructions to be carried out in order to solve a given problem. Instructions are telling what tasks are to be performed and the algorithm serves as a codification of the problem through a series of finite, consistent and rational steps [1].

Procedural modeling is a computer-aided generative system that can be simply defined to be content production by means of a procedure or a program. It is making use of a wide variety of techniques that can produce a specific type of content based on a set of input parameters in a defined degree of automatization. The procedural modelling has been an active subject especially in the videogames industry with capacity to produce complex virtual environments including road networks and urban settings. It is also applied in various areas such as modeling of plants, landscape, terrain, buildings, urban areas, road networks, rivers, or art creation. With the use of procedural modelling, considerable amount of resource of man skilled labor can be drastically reduced and expertise and knowledge dependent efforts can be concentrated on elaborating automatically created models by adding and altering particularities and details that might make them closer to expected results [2].

Many procedural models are essentially generative representations either of processes inspired by nature, such as plant development, or of man-centered processes, such as building design or urban developments. Due to the stochastic nature of the methods employed by procedural modeling a wide variety of results can be created from one set of input parameters [2]. This gives the procedural modelling its potential to reduce the amount of modeling effort required to create digital content. The use of the "procedural modelling" approach in the fields of architecture, urban planning and archaeology is generally based on the notions of "shape grammar" or "style grammars" approaches and has great potential as well in the field of architectural heritage modelling as it enables to cope with complexities and difficulties specific to this field.

Shape grammars are applications in which shapes are presented as design descriptions and transformed according to a rule based formalism [3]. Generation process can be modeled on the transformations of shapes. A shape grammar contains vocabulary, a set of shape rules and an initial shape. Form alternatives can be generated by applying the shape rules recursively to the initial shape. Stiny is considered the inventor and one of the pioneers of the shape grammar approach in architectural form generating through computer processed systems [4]. Eloy and Duarte provide a comprehensive background and examples of the shape grammar principles applied to building design [5]. Shape grammars are used in the field of vernacular housing by Flemming for Queen Anne Houses [6], Cagdas explored Turkish traditional housing patterns [7] and Colakoglu has made use of the shape grammar principles for translating the Turkish traditional house patterns and components to contemporary housing context [8]. 
Yong et al. describe a method to create a style in the form of Southeast Chinese vernacular houses using an extended shape grammar. The grammar used is hierarchically planned which is starting at city level, then producing streets, housing blocks, roads, and in further productions houses with components such as gates, windows, walls, and roofs. Through a number of controlling rules (defining component ratio constraints etc.), the validity of the buildings can be evaluated. Applying of this grammar system enables generation of a typical traditional Southeast Chinese town. The success of the system is closely related with the inherent grammar (building style) of these towns which are very rigidly structured [9].

An ontology based solution for procedural generation of ancient structures, specifically the so called "domus" roman houses configured by rectangular floor plans has been exemplified by Adao [10]. This approach implements a working methodology that relies on an abstract ontological specification for buildings, foreseeing the possibility of extension to other architectonic styles. Ontologies can be defined to be knowledge structures capable of describing a system, namely the relations between its parts. They have been successfully applied in different solutions that require the use of virtual models and environments. Ontology based procedural modelling is concerned with the rapidly and faithful visualization of virtual structures disregarding imperceptible details. The entire generation process relies in a set of definition and restriction rules to achieve the virtual building.

\subsection{Proposed Form Finding Methodology}

A methodology inspired by the computer-aided form generation systems is proposed in this paper to induce a shape grammar based approach to generate forms of the traditional Siirt cas houses, mainly to distinguish and extricate the authentic building forms from additional components and/or to deduce missing parts. This system is mainly based on the consideration that the authentic forms of the buildings can be generated with use of the identified basic forms and shapes and their inherent rule-based incremental development/expansion pattern or grammar. The formalization of the form finding procedure shall enable modelling of the authentic building forms and urban texture with relatively less information through use of less precise measurement and broad visual analysis and description (Fig. 1).

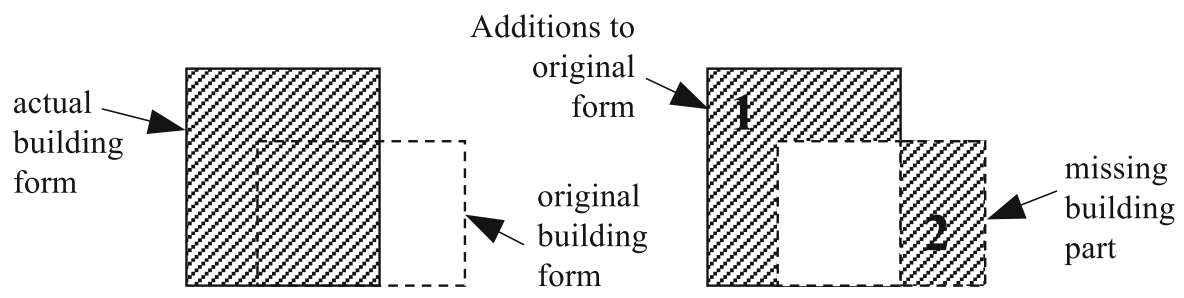

Fig. 1. The proposed methodology aims to deduce the original building form through identifying (1) the extrinsic additions to authentic form and (2) lost (missing) original building parts. 
For this purpose, the extensively encountered room sizes and ratios of the rectangular shaped spaces' edge lengths forming the building plan have been identified and categorized to be compared with computer generated rectangular forms within building boundaries. Nonconforming shapes and layouts are eliminated. Eligible found building plans have been compared with pre-identified shapes to be able to judge the existence of additions or missing parts of the actual buildings.

\section{Evaluation of Siirt Cas Houses}

\subsection{General Characteristics}

"Cas" houses are without much doubt the most apparent and predominant traditional housing style of the Siirt Province and neighboring regions in South East Turkey. The name "cas" is originated from the name given to the mortar which is in fact a material produced through a process consisting of grinding, burning and processing the lime stone which is constituting the characteristic geological soil formation in the region.

Cas houses are typically two to three floor buildings in rectangular shapes, getting narrower upwards in the form of cut rectangular pyramid. The structural composition stands on loose and irregular stone walls erected with cas mortar; slabs are formed either with dome or vault shaped stone or with vertically placed round wooden beams covered again with a layer of cas mortar joined earth or stone. Same cas mortar is used for exterior façade plastering which is giving the yellowish white color to these houses.

The majority of the urban texture in the historical city center of the Siirt Province is constituted of cas houses although they are extremely modified and degenerated in actual situation. These buildings have lost their original form due to mainly to additions and modifications through use of clay or concrete bricks and reinforced concrete structural extensions and additional floors.

Apart from a number of examples in Siirt city center, relatively well preserved cas houses can be seen at East and North parts of the city, extensively at Tillo and Şirvan districts, less frequently in Pervari on the East side and Eruh on the South part and rarely in Baykan at Northwest and Kurtalan at the West side as the geological sub soil formation starts to change. Tillo District center and related villages probably contains the highest number of cas houses in good condition, namely in İkizbağlar (Tom), Dereyamaç (Fersaf), Çınarlısu (Hantrant) and Çatılı (Sinep) together with Halenze (Bağtepe) district on the road leading from Siirt to Tillo.

\subsection{Typology of Cas Houses}

The typology of a cas house basically relates to the derivation of a single cas mortar joined stone walled module in rectangular shape at plan and cut pyramidal form in three dimension. This modules are in fact spaces in the form of cells of 10 to $15 \mathrm{~m}^{2}$ footprint area at an average inner height of around $3 \mathrm{~m}$. The roof of the cells are covered with either vault shaped mortar joined stone or with wooden beams. Side walls of this cell has identical and rhythmic openings used either for doors or windows. The sizes of these openings vary around $60-80 \mathrm{~cm}$ in horizontal plane and the height of a 
window is in general double of its horizontal dimension. When the opening is a doorway, the transom of the door is at the same level of the top of the window. Some very much encountered plan forms are shown in Fig. 2 with typical cross sections. One edge of the typical cell measures generally around $450 \mathrm{~cm}$ and contains three openings used as door or window; whereas the other edges may have an average length varying from $250 \mathrm{~cm}$ to $600 \mathrm{~cm}$.
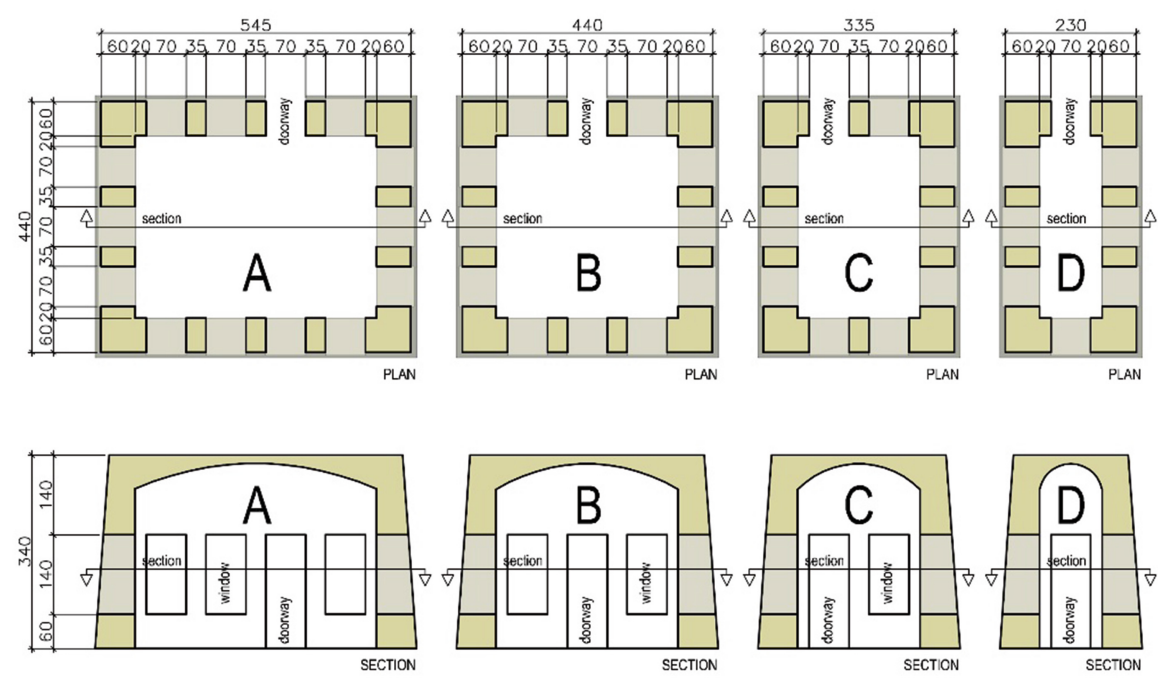

Fig. 2. Typical plans and sections of single floor cas house modules in different sizes varying according to the number of the façade openings.

Cas houses evolved in time through incremental enlarging on an expansion pattern. This incremental expansion of a cas house can be both in horizontal or vertical directions. In horizontal expansion the footprint of the building is enlarged through addition of rooms. Vertical expansion is by adding floors accessed through stairs built at the exterior of the initial cell. Both forms of expansions follow a set of rules originating from the specific geometrical character and structural properties of the houses.

It is possible to distinguish mainly two types of cas houses which are varying possibly according to the owners' economical wealth and status. Some houses are in the form of detached mansions generally isolated from other houses, surrounded with a garden and in a regular square or rectangular form at two or three floor levels. Remaining samples of these houses are relatively well preserved and generally keeping their integrity.

Others belonging to less wealthier population are in dense urban settings, mostly using each other's walls to form clusters also enabling protection from the effects of the hot and arid climate to form narrow and shady streets. These examples found in the old city center of the Siirt Province are extremely modified through addition of rooms, spaces or floors with reinforced concrete structures. The evaluated types of cas houses in this paper mainly relate to this second group. 
Horizontal Development. Enlargement in horizontal plane is provided simply by joining other cells of same or different sizes to any direction to an existing cell. This kind of horizontal development of the cas houses is illustrated below. Regular dimensioning of the windows and doors facilitates enlargement by joining cells or in other words building new cells next to the existing ones (Fig. 3).
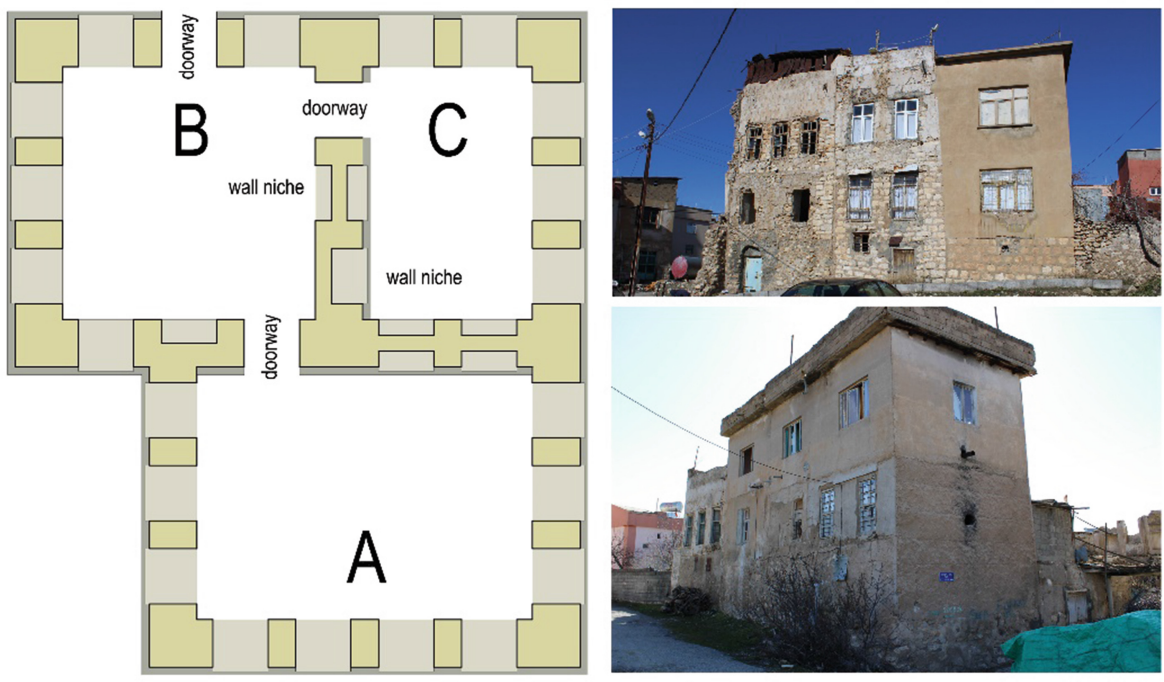

Fig. 3. Sample horizontal enlargement of the cas houses shown in schematic plans and in photos of the existing buildings.

In the internal arrangement after enlargement previously formed door or window openings are transformed to wall niches which are used in several ways such as cabinets, shelves or fire places (Fig. 4).
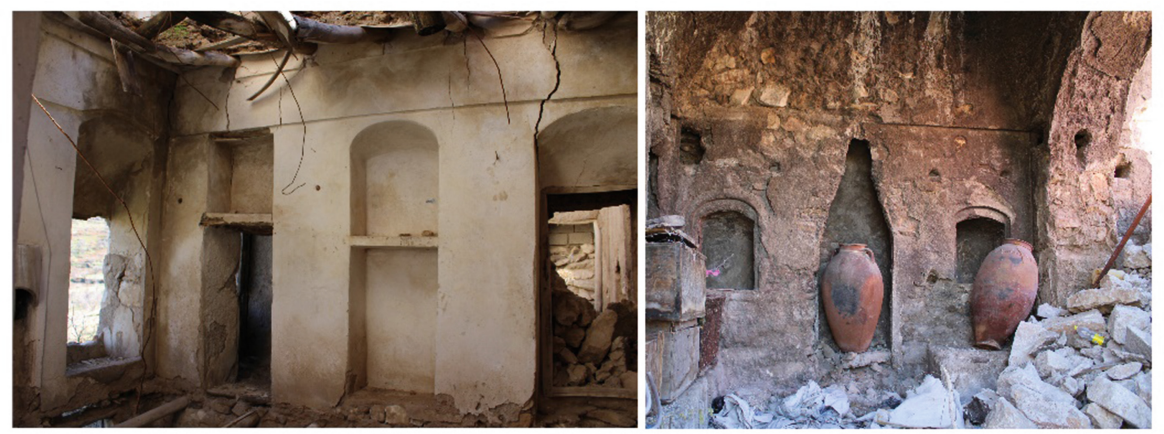

Fig. 4. Doors and windows transformed to wall niches used as shelves, cupboards or fire places. 
Vertical Development. Increasing the number of floors for cas houses is made through continuing the outer walls vertically and adding another cell on top of the existing one. Access to upper floor is made with a stone stair built next to the outer wall, mostly L shaped using two sides of the cell. The stair is covered again by a stone vaulted tunnel in most of the cases. Due to this tunnel the stair becomes an indoor space and another level of stair can later be added when forming an additional level. In most of the cases the maximum number of floors in a cas house is three floors including the ground floor (Fig. 5).
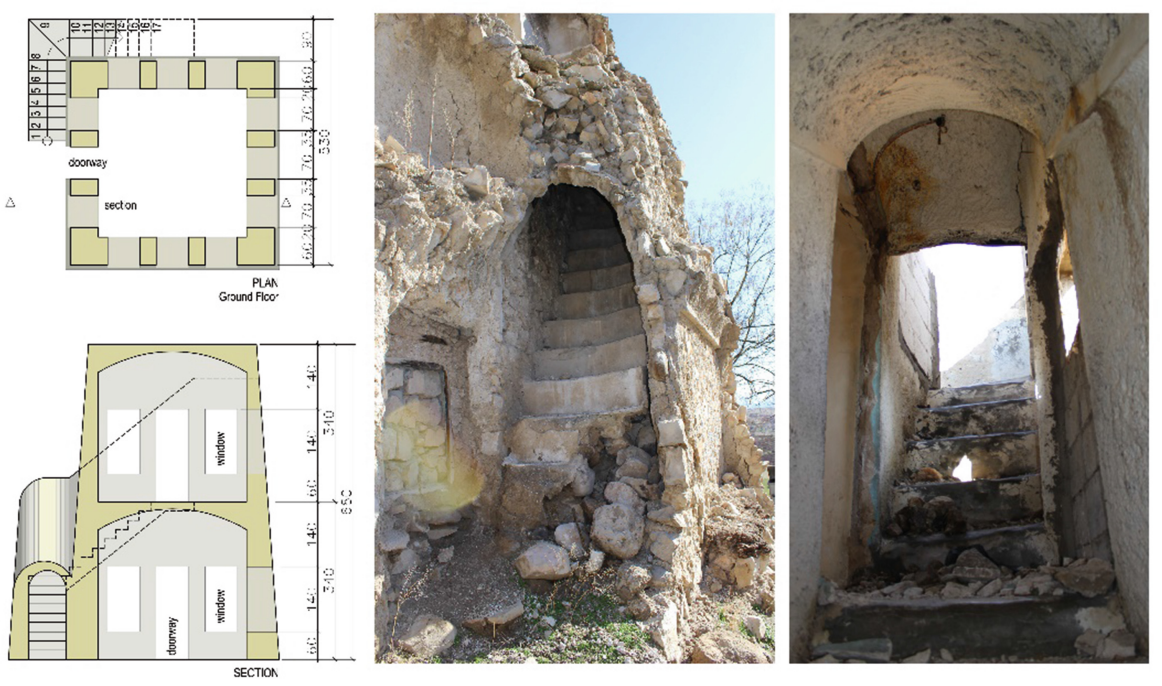

Fig. 5. Doors and windows transformed to wall niches used as shelves, cupboards or fire places.

Another highly characteristic component of the cas houses are the underpass structures called "sabat". This element is a tunnel like passage way covered by stone vault or by wooden beams used whenever a horizontal development of a cas house is likely to block an existing path. This type of an underpass is also quite useful to protect pedestrians from the effects of hot and arid climate of the region (Fig. 6).

\subsection{Translating Cas House Typology to Shape Grammars}

In relation with the typology analysis of cas houses summarized above, a shape grammar approach has been developed. Accordingly the initial shape in planar view is always a rectangular form defined as " $A$ " identified by the length of the long and short edges named as " $x$ " and " $y$ ". The rule for enlargement with other (appendage) cells (rooms) identified as " $\mathrm{B}$ ", " $\mathrm{C}$ " etc. in alphabetical order is juxtaposing other similar rectangular forms to one edge of the initial shape which can be "up", "down", "left" or "right". Derivation of appendages are identified with two parameters which are the "layout" and "alignment" with reference to a given initial or appendage shape. 

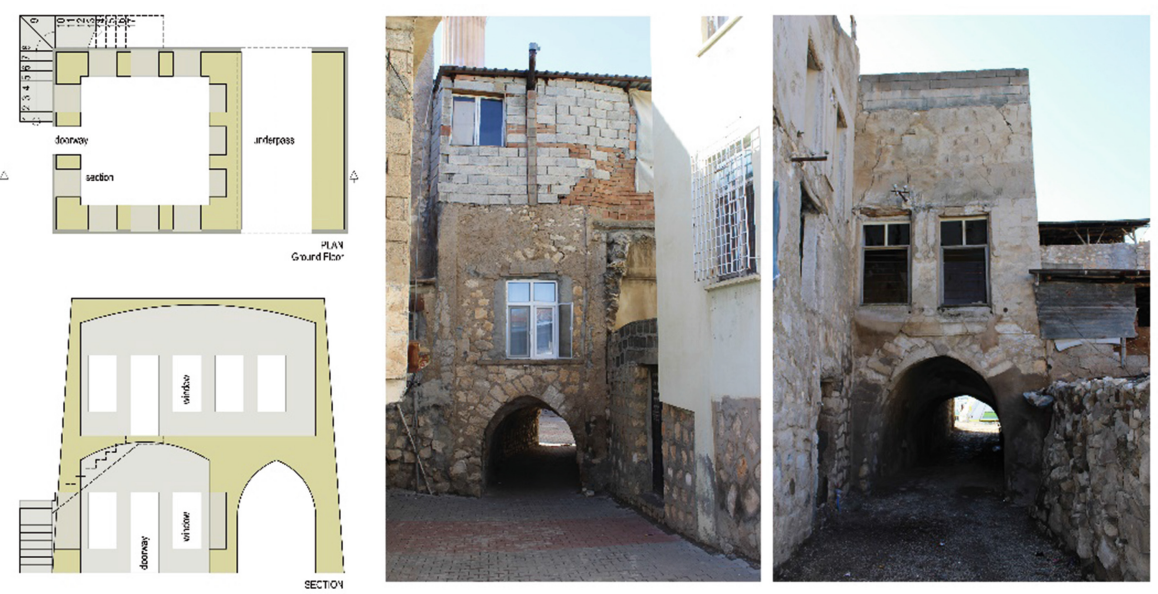

Fig. 6. Stone vaulted underpass structures at ground floor of the cas houses are called "sabat" in the local language of the region.

Table 1. Shape grammar for cas houses.

\begin{tabular}{l|l|l|l|l|l|l|l}
\hline Line no & Shape name & \multicolumn{2}{|l|}{$\begin{array}{l}\text { Edge } \\
\text { lengths }\end{array}$} & Shape type & Reference & Layout & Align \\
\cline { 3 - 6 } & & $\mathrm{x}$ & $\mathrm{y}$ & & & & \\
\hline 01 & A & 400 & 300 & Initial & Null & Null & Null \\
\hline 02 & B & 300 & 500 & Appendage & A & Right (R) & Top (T) \\
\hline 03 & C & 600 & 400 & Appendage & A & Down (D) & Right (R) \\
\hline 04 & D & 600 & 300 & Appendage & B & Down (D) & Left (L) \\
\hline 05 & Stair & 600 & 300 & Stair & C & Down (D) & Left (L) \\
\hline 06 & Sabat & 300 & 300 & Sabat & D & Right (R) & Right (R) \\
\hline
\end{tabular}

Above given table derivate following building form when edge length values are entered as given as in the table (Fig. 7).

For multi-leveled buildings size and location of the stair can also be defined in the same table as shown in line 05. Whenever a path crosses the building, an underpass will be necessary to be placed in the building again with the same shape grammar table as illustrated in line number 06. The first floor of the building will in principle follow exactly the same units and layout in the ground floor due to the structural characteristics of the cas houses. 

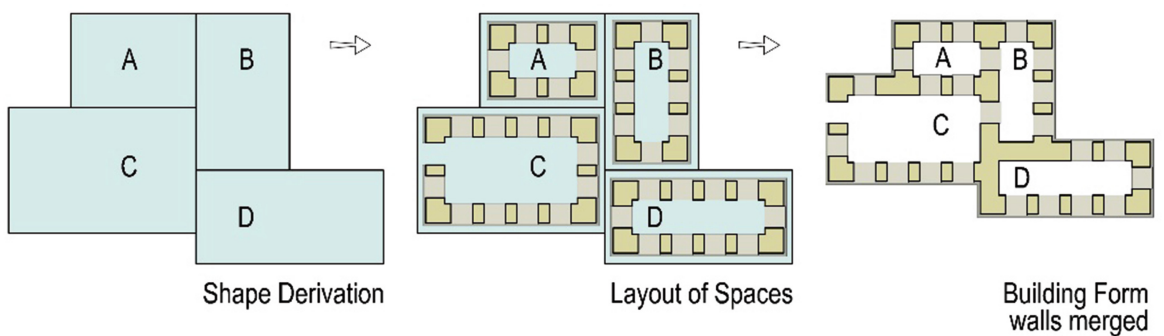

Fig. 7. Derivation of the size and layout of the cells and translation of the grammar to the building form in accordance with data given in Table 1.

\section{Description of the Proposed Form Finding System}

\subsection{Identification of the Problem}

The city center of the Siirt Province is formed of a dense urban texture almost wholly composed of cas houses degenerated through additions to existing buildings and/or demolishing of some parts of the authentic built environment. Identifying or modeling of the original form back in history is a quite complex task. The actual urban texture and some examples of modified traditional individual buildings are shown below (Figs. 8 and 9).

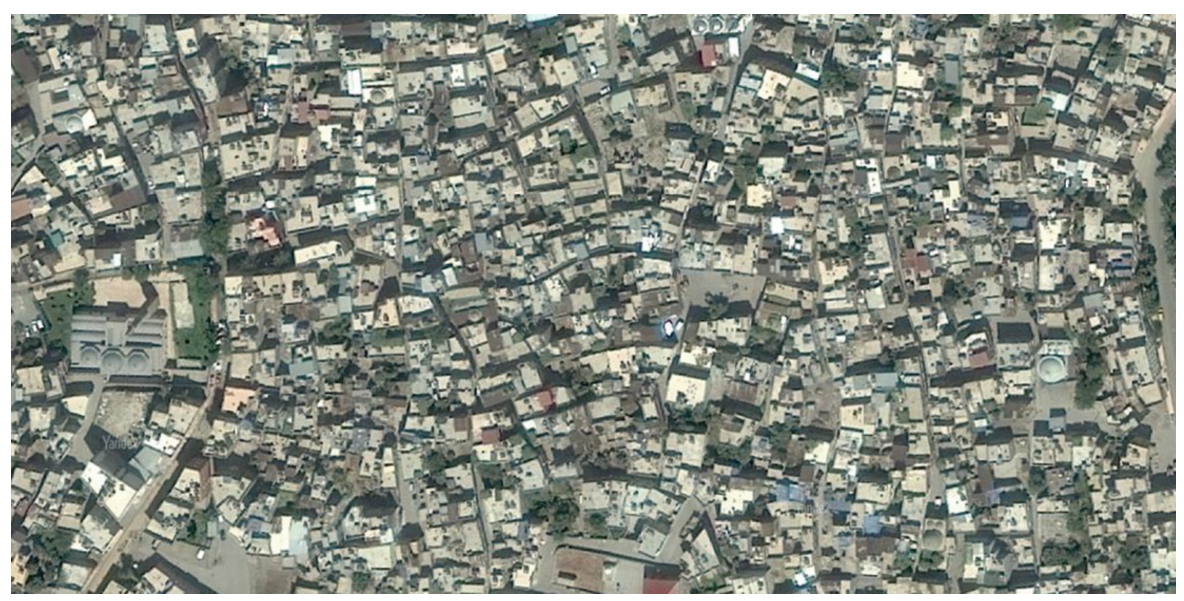

Fig. 8. Satellite view of the Siirt city center formed with buildings which are mostly originally composed of traditional cas houses [11]. 

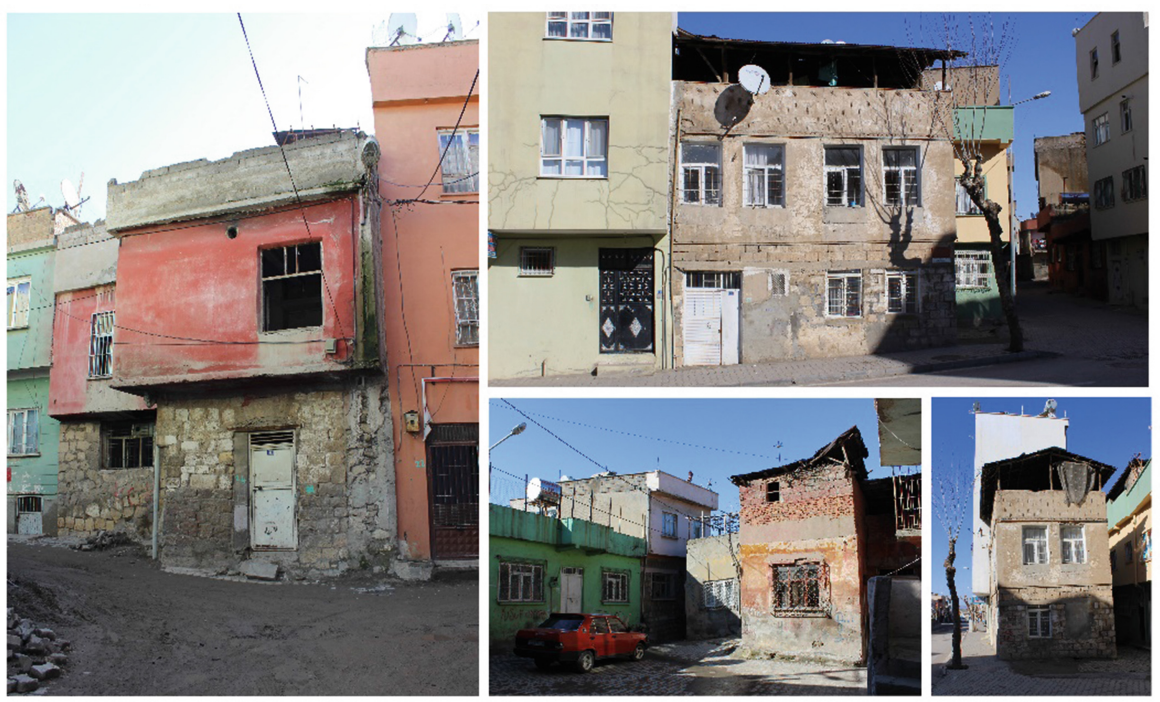

Fig. 9. Some examples of the cas houses in Siirt city center which are lost their original and authentic form and properties.

Considering the complexity of the urban texture and the degree of modifications incorporated, a simplified way of form finding to deduce the original morphology of the built environment is proposed.

\subsection{Form Finding System}

The proposed system is based on the principle of plan layout generation composed of predefined existing space forms through processing the information obtained in the form of exterior foot print shape and size of the buildings and verification of generated plans for accuracy with existing other parameters to be received of the site. Consequent to the revealing of shape framing the outer (footprint) boundaries, the first step is the extension of all the lines at reflex angles until they cross a boundary line. This first step is labeled "angle extending". Resulting form is composed of rectangular tiles filling the outer boundaries. These tiles are enumerated as given in illustration below where eleven (11) tiles are produced. This method is similar to that employed by Camozzato et al. for their procedural floor plan generation from building sketches [12].

In the second step, the rectangular tiles are forming other larger rectangles with tiles next to them in an orthogonal manner at both $\mathrm{x}$ and $\mathrm{y}$ directions. Possibilities for tiles numbered from 1 to 4 are given within the $2^{\text {nd }}$ frame of the figure below as examples. In the third level of the process the form finder searches alternatives for merging the tiles formed at the $2^{\text {nd }}$ step with each other to produce larger rectangular forms. For each of the alternatives the outer boundaries are filled with other shapes which are not overlapping with previously produced rectangular shapes. 
Upon derivation of all possible alternatives the nonconforming shapes in terms of dimensions and ratios with reference to predefined cas house room patterns are eliminated and marked as alien (shown with red color in Fig. 10).

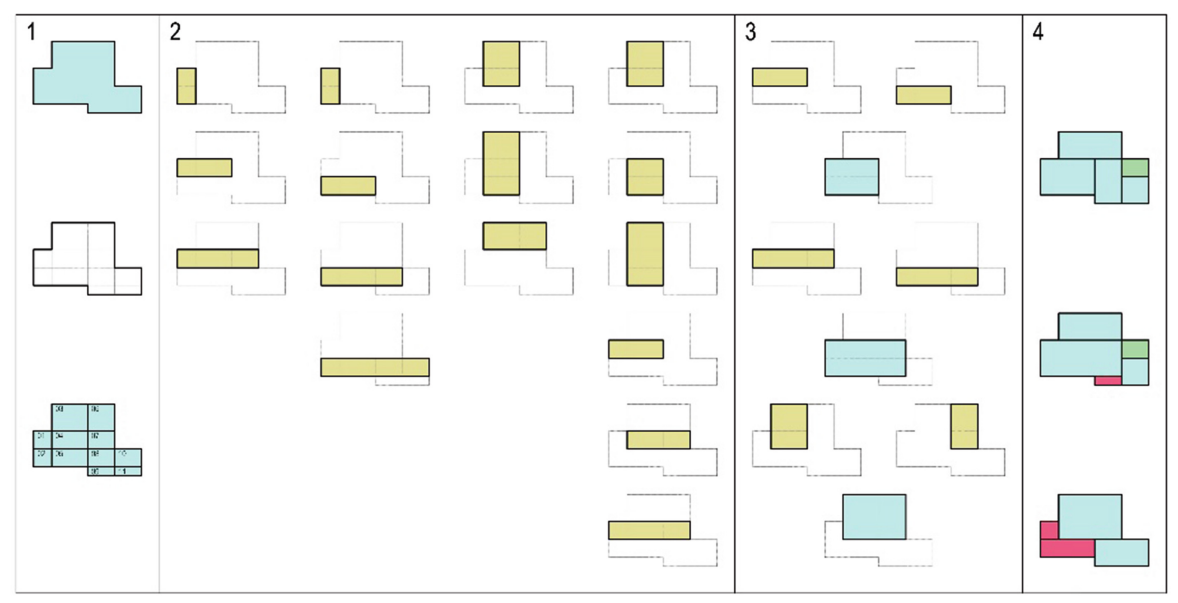

Fig. 10. Example of procedural form generation from a given outer boundary shape to deduce alien appendices to buildings. (Color figure online)

The process is also able to propose extensions (shown in green color in figure above) in order to establish similarity of a generated form with predefined forms. Those are interpreted as possibly missing parts of the authentic buildings.

\subsection{Expected Results}

The form generating system is expected to provide a number of plan alternatives generated through the information that relates to the outer boundary shape and approximate dimensions of the buildings that are revealed on site or through satellite maps. A portion of the generated alternatives are eliminated and some are marked with suspected unoriginal additions or suspected missing parts. Broad visual inspection of the real subject is expected to enable prompt revealing of the original composition of the house with considerably reduced time and effort consumption.

\section{Conclusion}

The mathematical modeling of cas houses aimed to enable an automated system helping the deduce the authentic form of the buildings and relevant urban texture. Considering the quantity and the complexity of the individual buildings and the physical environment they form, a need for an automated system to deduce the authentic morphology of the built environment is essential. 
The inherent style and grammar of the Siirt cas houses have remarkable potential for the development of such a system due to their orthogonal and incremental expansion pattern. The system can be further developed to cover as well the other essential building elements such as entrance doors, windows, wall niches, stairs, underpasses etc. to respond to detailing needs of the modeling process. With study of adjacent buildings and other elements of the built environment an incremental modeling of the authentic urban texture can be obtained.

\section{References}

1. Rajamaran, V.: Computer Programming in C. Prentice Hall of India, New Delhi (2006)

2. Smelik, R.M., Tutenel, T., Bidarra, R., Benes, B.: A survey on procedural modeling for virtual worlds. Comput. Graph. Forum. http://hpcg.purdue.edu/bbenes/papers/Smelik14 CGF.pdf. Accessed 26 Apr 2018

3. Ediz, O., Cagdas, G.: A computational architectural design approach based on fractals at early design phases. In: Dikbas, A., Scherer, R. (eds.) eWork and eBusiness in Architecture, Engineering and Construction, pp. 1055-1062. Taylor \& Francis, Routledge (2004)

4. Stiny, G.: Introduction to shape and shape grammars. Environ. Plan. B 8, 343-351 (1980)

5. Eloy, S., Duarte, J.P.: Inferring a shape grammar: translating designer's knowledge. Artif. Intell. Eng. Des. Anal. Manuf. 28, 153-168 (2014)

6. Flemming, U.: More than the sum of parts: the grammar of Queen Anne houses. Environ. Plan. 14, 323-350 (1987)

7. Çagdas, G.: A shape grammar: the language of traditional Turkish houses. Environ. Plan. $\mathbf{2 3}$ (5), 443-464 (1996)

8. Colakoglu, M.B.: Design by grammar: an interpretation and generation of vernacular hayat houses in contemporary context. Environ. Plan. 32, 141-149 (2005)

9. Yong, L., Congfu, X., Zhigeng, P., Yunhe, P.: Semantic Modeling Project: building vernacular house of southeast China. In: VRCAI 2004: Proceedings of the ACM SIGGRAPH International Conference on Virtual Reality Continuum and its Applications in Industry, pp. 412-418. ACM, New York (2004)

10. Adao, T., Magalhaes, L., Peres, E.: Ontology-Based Procedural Modelling of Traversable Buildings Composed by Arbitrary Shapes. Springer, Cham (2016). https://doi.org/10.1007/ 978-3-319-42372-2

11. Yandex Maps. https://yandex.com.tr/harita/103878/siirt/. Accessed 27 Apr 2018

12. Camozzato, D., Dihi, L., Silvera, I., Marson, F., Musse, S.: Procedural floor plan generation from building sketches. Vis. Comput. Int. J. Comput. Graph. 31(6-8), 753-763 (2015) 
Open Access This chapter is licensed under the terms of the Creative Commons Attribution 4.0 International License (http://creativecommons.org/licenses/by/4.0/), which permits use, sharing, adaptation, distribution and reproduction in any medium or format, as long as you give appropriate credit to the original author(s) and the source, provide a link to the Creative Commons licence and indicate if changes were made.

The images or other third party material in this chapter are included in the chapter's Creative Commons licence, unless indicated otherwise in a credit line to the material. If material is not included in the chapter's Creative Commons licence and your intended use is not permitted by statutory regulation or exceeds the permitted use, you will need to obtain permission directly from the copyright holder. 